\title{
Aeolus Calibration, Validation and Science Campaigns
}

\section{Thorsten Fehr ${ }^{1}$, Vassilis Amiridis ${ }^{2}$, Sebastian Bley ${ }^{3}$, Philippe Cocquerez ${ }^{4}$, Christian}

Lemmerz $^{5}$, Griša Močnik ${ }^{6}$, Gail Skofronick-Jackson, and Anne Grete Straume ${ }^{1}$

${ }^{1}$ ESA, Noordwijk, Netherlands

${ }^{2}$ NOA, Penteli, Greece

3ESA, Frascati, Italy

${ }^{4}$ CNES, Toulouse, France

${ }^{5}$ DLR, Oberpfaffenhofen, Germany

GUniversity of Nova Gorica, Ajdovščina, Slovenia

${ }^{7}$ NASA, Washington, USAEuropean Space Agency

Paper EGU2020-19778, Session AS1.35 - Aeolus data and its application

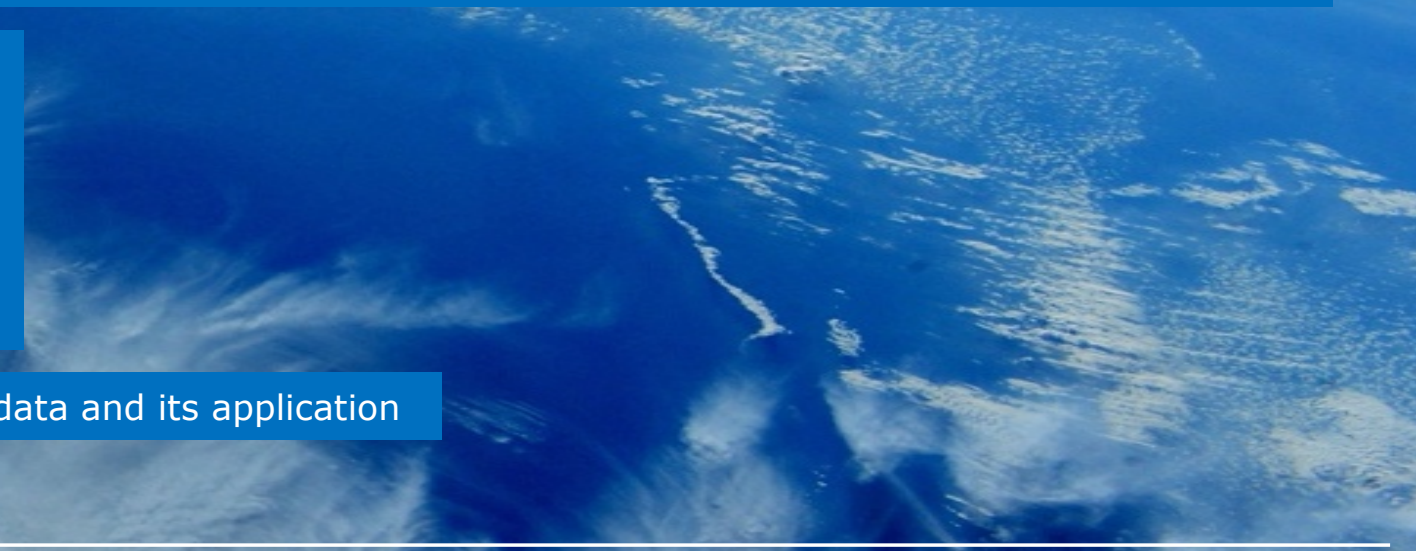

- IU+ー 
For a comprehensive overview of the Aeolus Mission and its status see:

T. Parrinello et al., ESA's Wind Mission Paper EGU2020-4091. Session AS1.35 - Aeolus data and its application 


\section{Main Aeolus Product - Line-of-Sight Wind}

Level 2B

Rayleigh Wind Profiles 02 January 2020
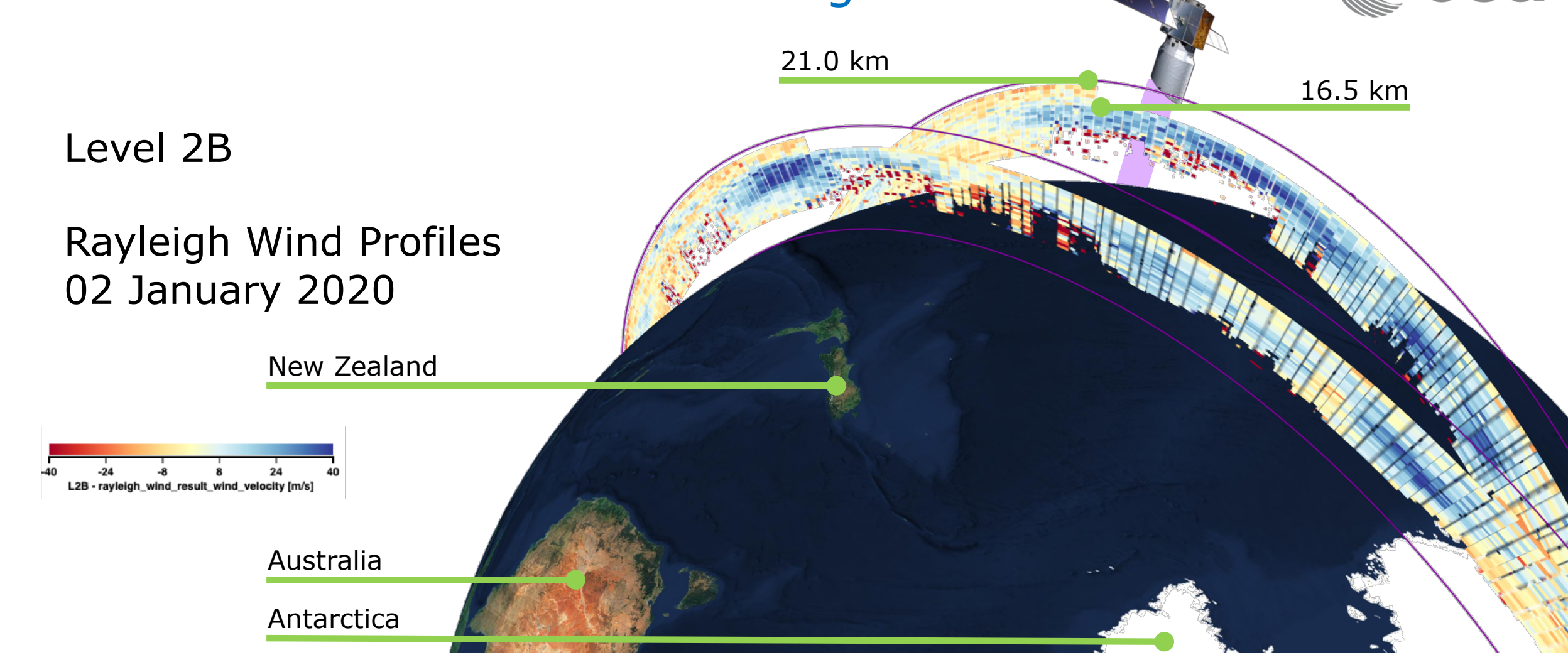

\section{$16.5 \mathrm{~km}$}

cesa

\section{$16.5 \mathrm{~km}$}


Aeolus Products - Optical Products

Level 2A

Particle Ext. Coef. Profiles 02 January 2020
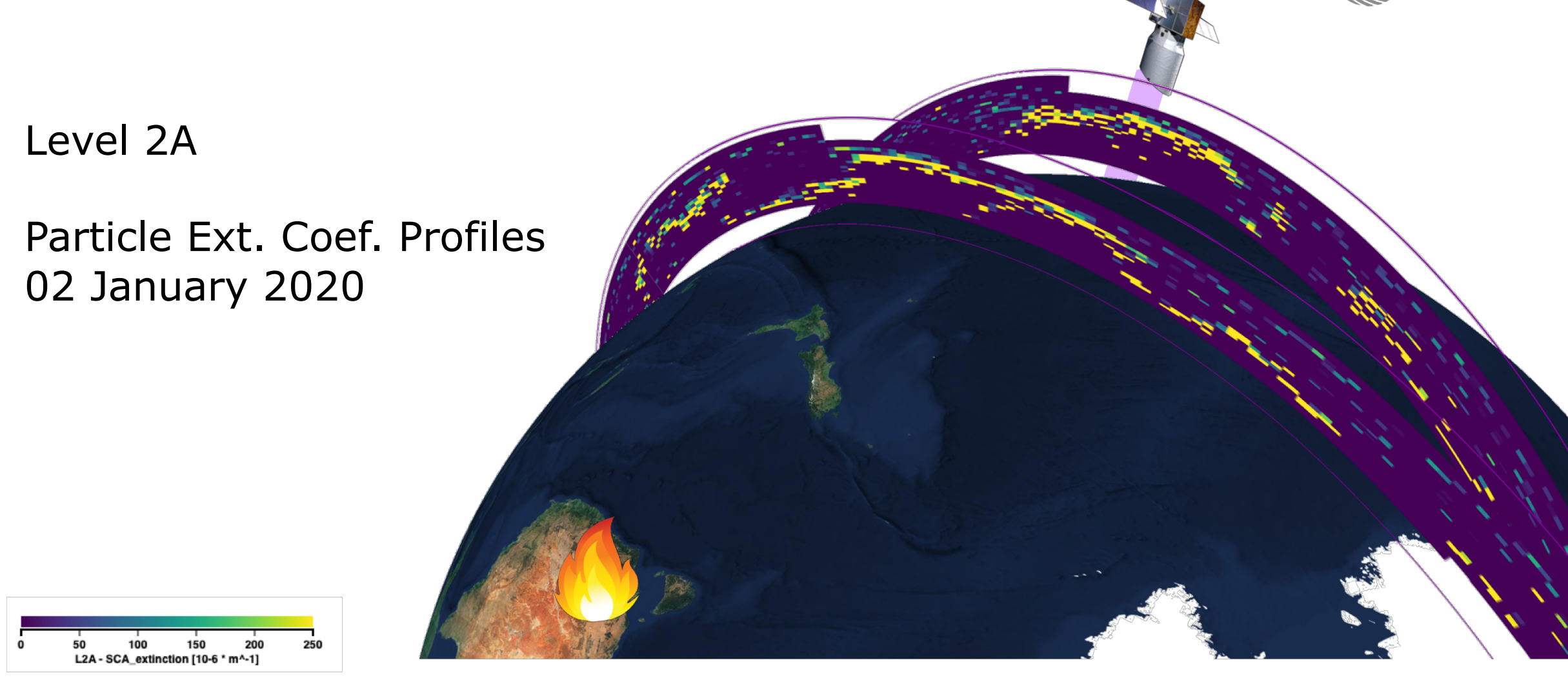

cesa 


\section{Aeolus Airborne Campaigns since Launch}

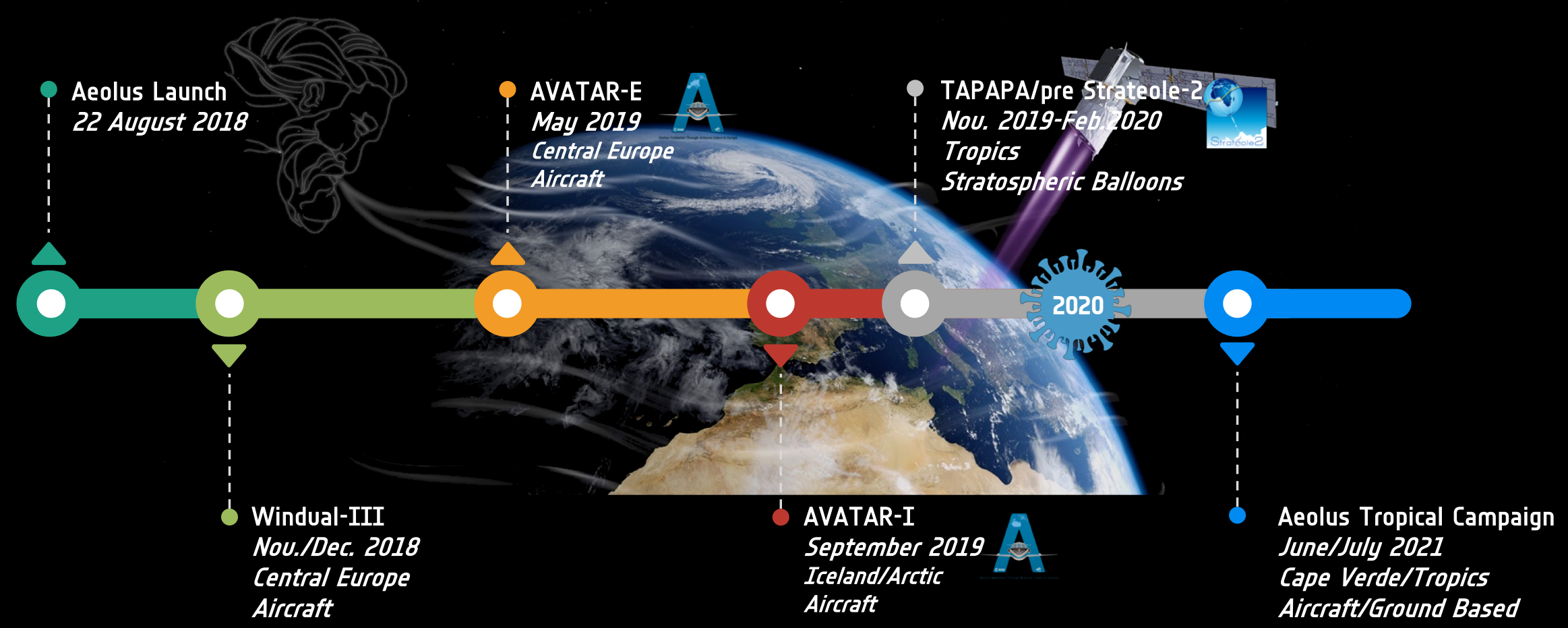




\section{Aircraft Campaigns before Launch (DLR/NASA/CNES) esa}
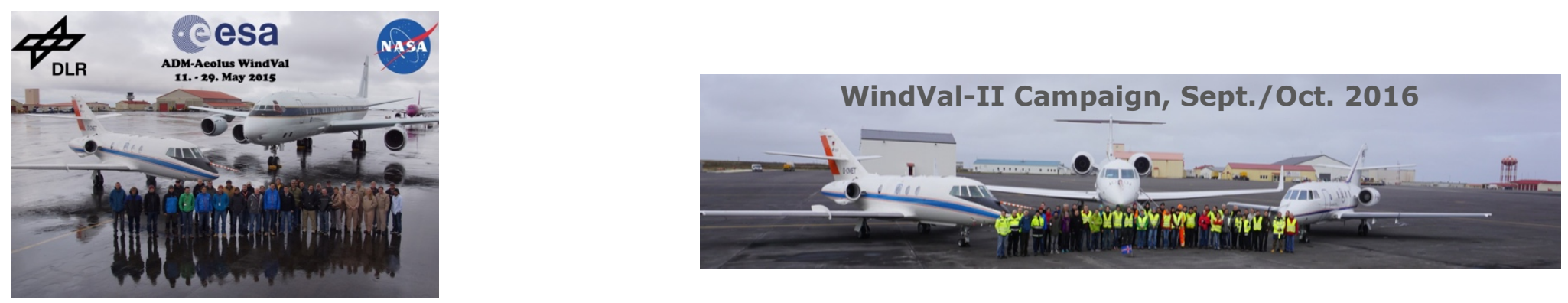

Aircraft Campaigns since Launch (DLR)

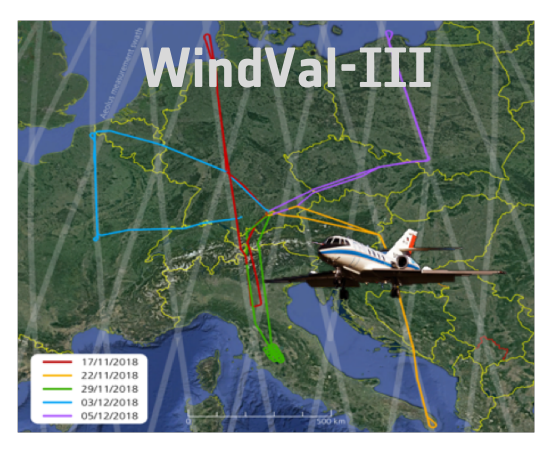

ESA UNCLASSIFIED - For Official Use

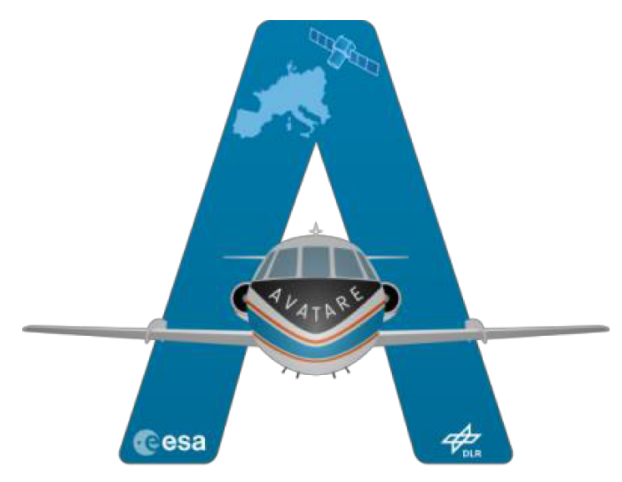

Aeolus Validation Through Airborne Lidars in Europe

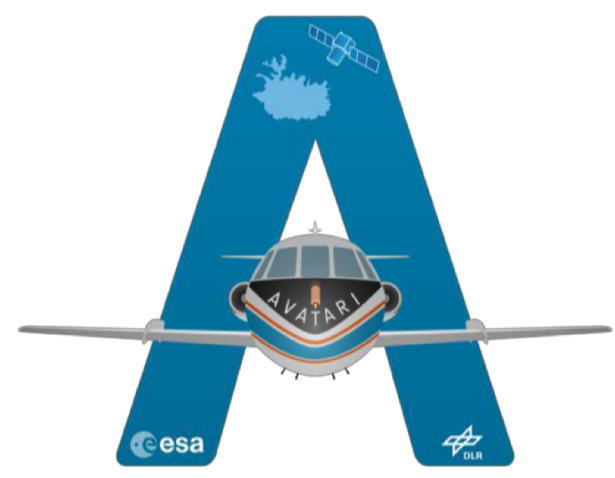

Aeolus Validation Through Airborne Lidars in Iceland 


\section{DLR Falcon with ALADIN Airborne Demonstrator A2D and 2- $\mu \mathrm{m}$ wind lidar}

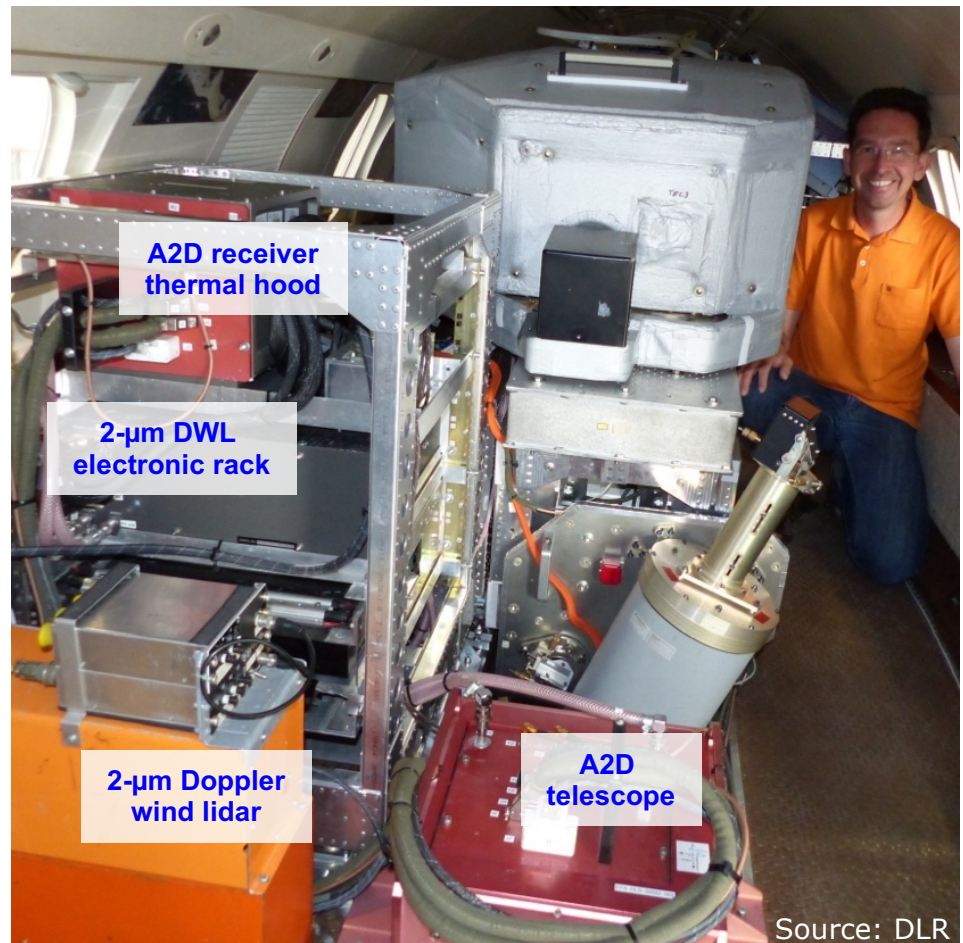

ESA UNCLASSIFIED - For Official Use

\begin{tabular}{|c|c|c|}
\hline & $\begin{array}{l}\text { ALADIN airborne } \\
\text { demonstrator }\end{array}$ & $\begin{array}{l}\text { 2- } \mu m \text { Doppler wind lidar DWL } \\
\text { ("Reference System") }\end{array}$ \\
\hline Wavelength & $354.9 \mathrm{~nm}$ (UV) & $2.022 \mu \mathrm{m}(\mathrm{IR})$ \\
\hline Backscatter & molecules, aerosol, clouds & aerosol, clouds \\
\hline Wind & line-of-sight LOS, $20^{\circ}$ & $\begin{array}{l}\text { LOS, hor. wind vector, } \\
\text { vertical wind w }\end{array}$ \\
\hline Vertical res. & $250 \mathrm{~m}-2 \mathrm{~km}$ & 100 m / 500 m (for Aeolus) \\
\hline Time res. & $14 s(+4 s)$ & $1 \mathrm{~s}$ LOS, 30 - 40 s vector \\
\hline $\begin{array}{l}\text { Horizontal res. } \\
@ 200 \mathrm{~m} / \mathrm{s}\end{array}$ & $3.6 \mathrm{~km}$ & $\begin{array}{l}200 \mathrm{~m} \text { LOS, } 6-8 \mathrm{~km} \text { vector, } \\
42 \mathrm{~km} \text { (for Aeolus) }\end{array}$ \\
\hline Precision & $\begin{array}{l}2 \mathrm{~m} / \mathrm{s} \text { (mol.) } \\
1.5 \mathrm{~m} / \mathrm{s} \text { (aer.) }\end{array}$ & $\begin{array}{l}<1 \mathrm{~m} / \mathrm{s} \text { vector } \\
<0.3 \mathrm{~m} / \mathrm{s} \text { vertical }\end{array}$ \\
\hline Accuracy & $0.5-1 \mathrm{~m} / \mathrm{s}$ & $<0.1 \mathrm{~m} / \mathrm{s}$ \\
\hline
\end{tabular}

Reitebuch et al. (2009), JAOT; Reitebuch (2C12): Springier; Lux et al. (2018), AMT, Marksteiner et al. (2018), Remote Sensing, Witschas et al (2017), JAOT 


\section{Validation throughout the mission}

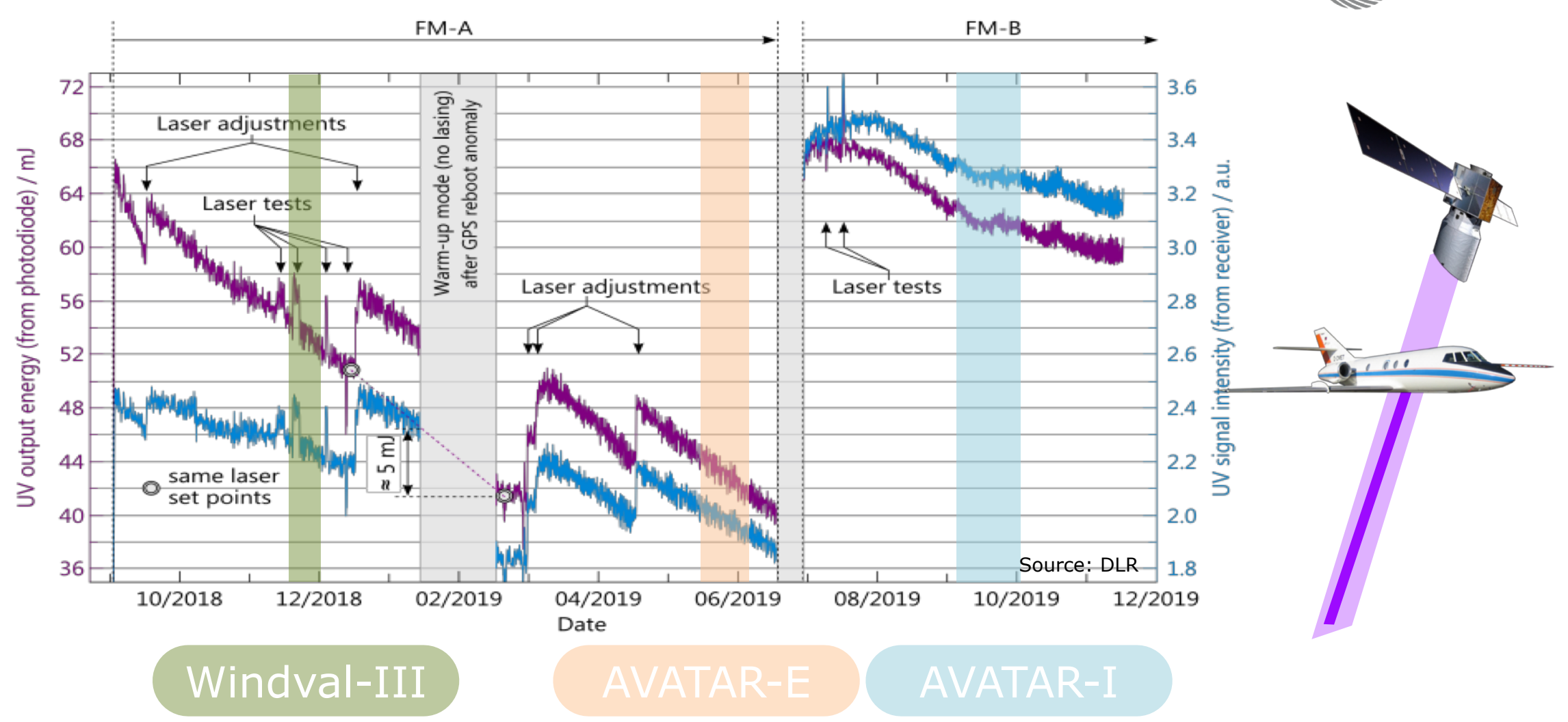




\section{Single Underflight and Statistical Analysis (DLR)}

UF \#5, first on descending orbit

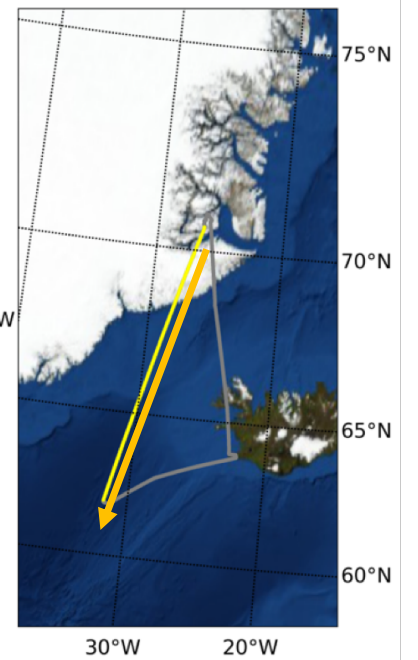

\section{First results} available already during campaign!
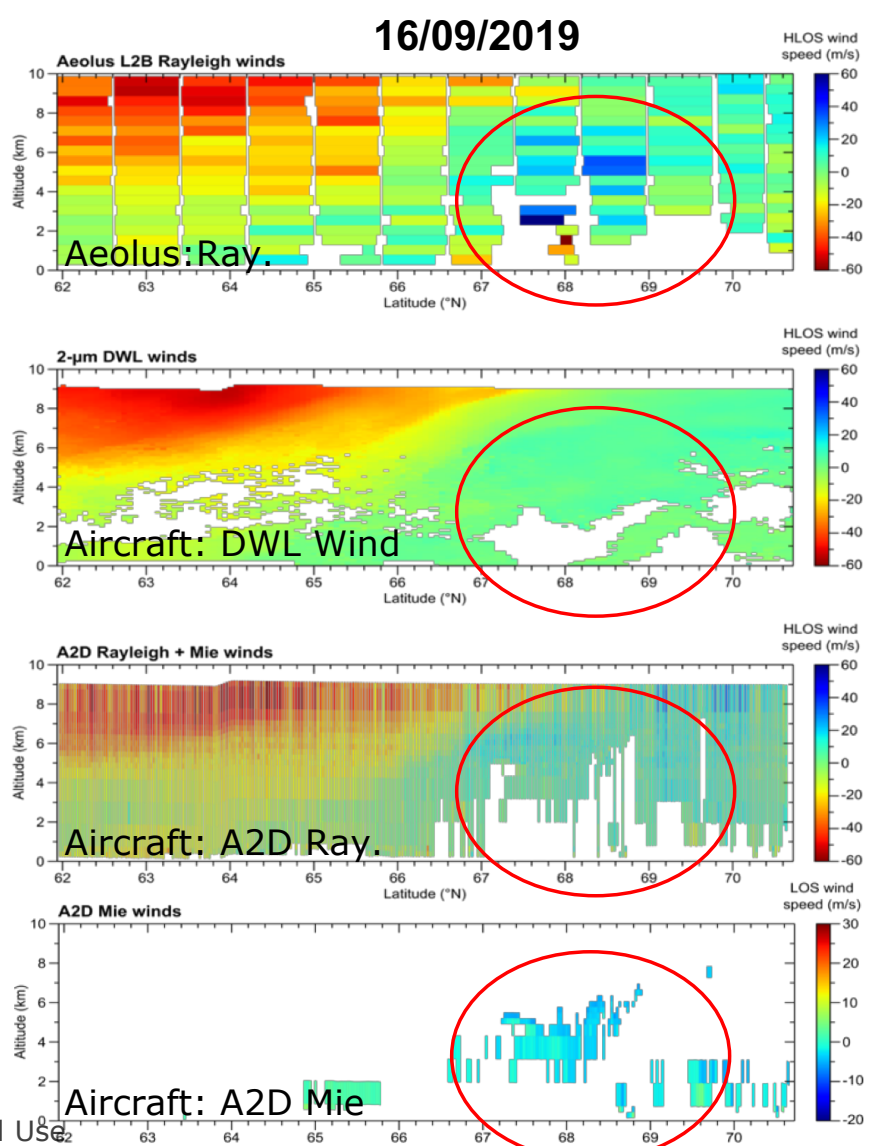

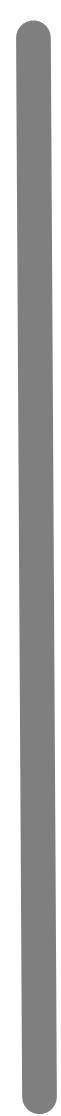

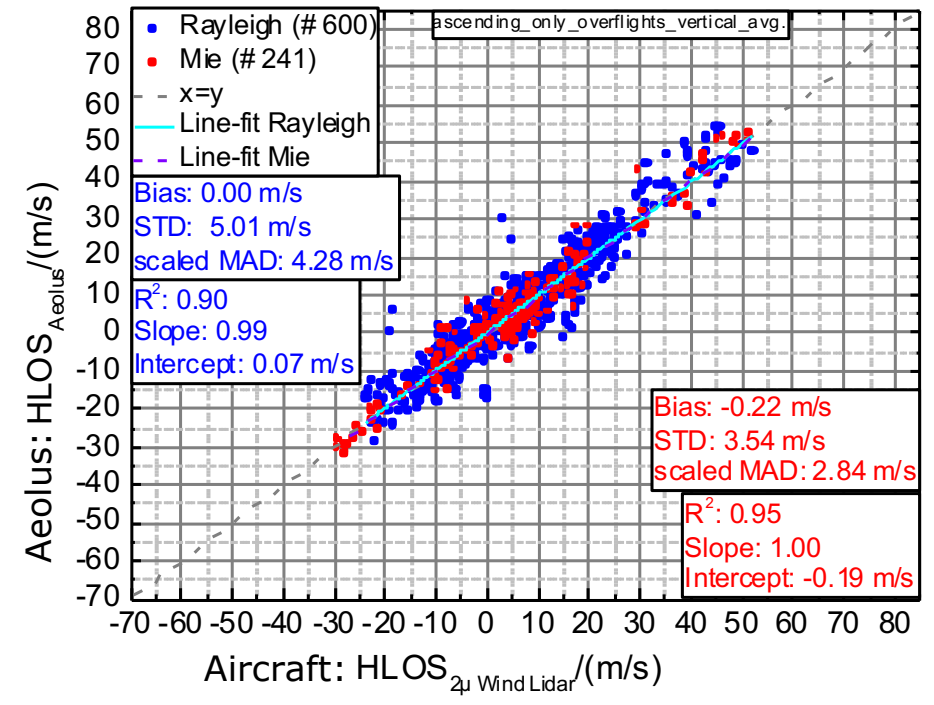

\section{AVATAR-I}

Preliminary Data Only flight legs with ascending orbit 
Key results from WindVal-III, AVATAR-E/-I (DLR)

\begin{tabular}{|c|c|c|c|c|}
\hline Preliminary Results & \multicolumn{2}{|c|}{ Rayleigh Winds } & \multicolumn{2}{c|}{ Mie Winds } \\
\hline Orbit & Bias & Radom & Bias & Radom \\
\hline Ascending & $0.0 \mathrm{~m} / \mathrm{s}$ & $4.3 \mathrm{~m} / \mathrm{s}$ & $-0.2 \mathrm{~m} / \mathrm{s}$ & $2.8 \mathrm{~m} / \mathrm{s}$ \\
\hline Descending & $1.8 \mathrm{~m} / \mathrm{s}$ & $3.9 \mathrm{~m} / \mathrm{s}$ & $-0.6 \mathrm{~m} / \mathrm{s}$ & $2.5 \mathrm{~m} / \mathrm{s}$ \\
\hline
\end{tabular}

- Rayleigh random error scales with the range bin size $\rightarrow$ Poisson noise limited

- Mie random error does not scale with resolution $\rightarrow$ SNR driven

- Rayleigh random error AVATAR-E and -I similar, despite factor 1.5 in reported UV energy $\rightarrow$ higher solar background in September (Iceland, $66^{\circ} \mathrm{N}$ ) compared to May (Central Europe)

- Campaigns during mission implementation phase fundamental to the early Aeolus success

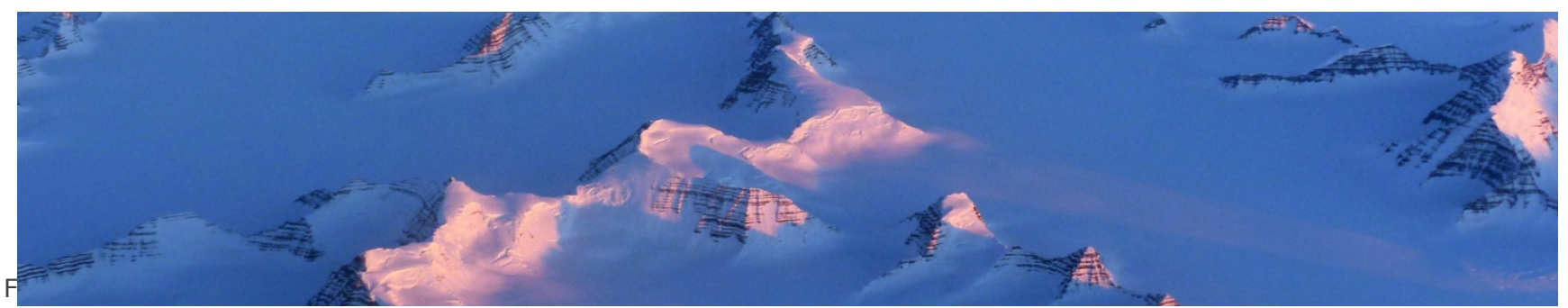




\section{TAPAPA / pre Stratéole-2 (CNES/LMD)}

\section{Objectives:}

- Few direct stratospheric wind observations exist, but are fundamental to understand the global circulation, in particular in the Tropics

- Support to Aeolus Cal/Val activities using wind observations from CNES stratospheric balloons during the LMD/CNES pre Stratéole-2 Campaign $2019 / 20$

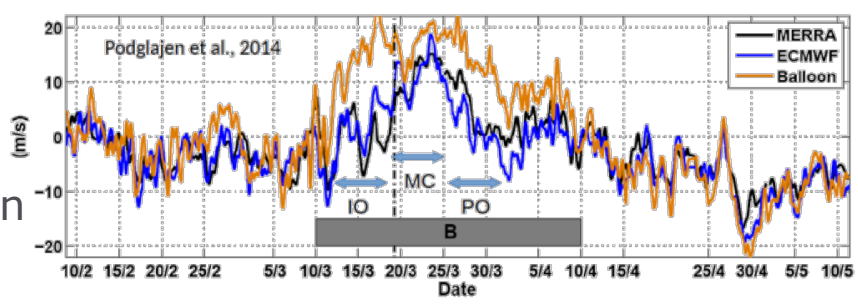

\section{Campaign Details:}

- Circum-terrestrial, 3-month stratospheric balloon flights in the Tropics

- Eight super-pressure long-duration balloons operating in the lower tropical stratosphere (18-20 km) in Nov./Dec. 2019 to Feb. 2020

- Pressure, temperature and GPS location every $30 \mathrm{~s}$ at flight level

- 3D winds deduced from successive GPS positions

- Data analysis ongoing

ESA UNCLASSIFIED - For Official Use

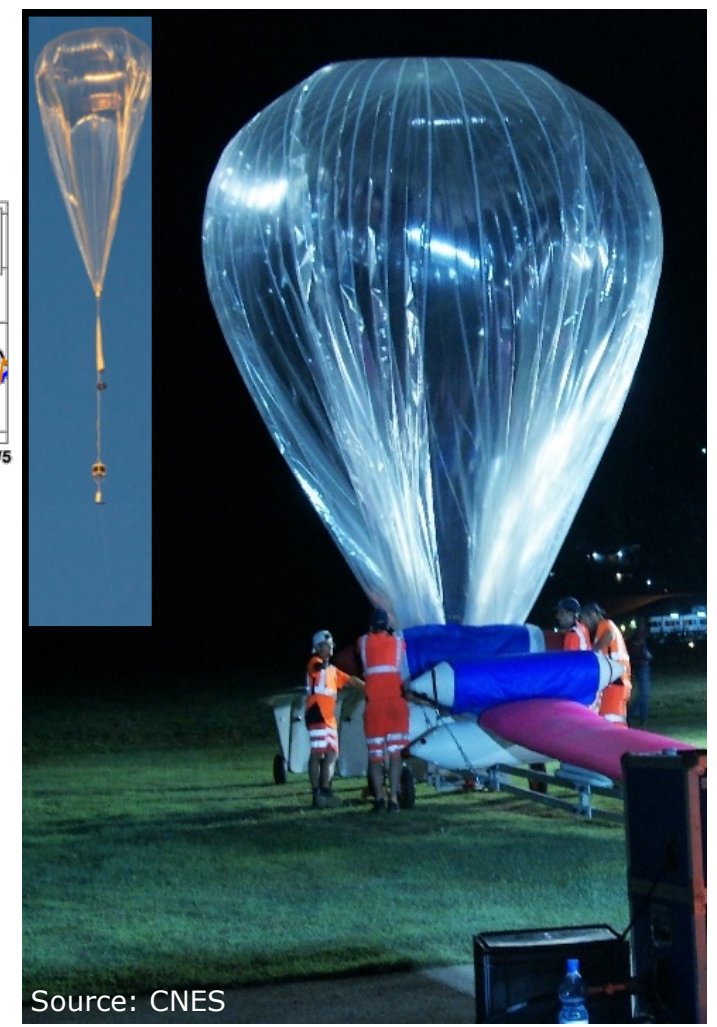

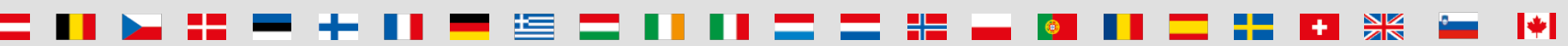




\section{TAPAPA / pre-Strateole-2 (CNES/LMD)}

\section{tesa}

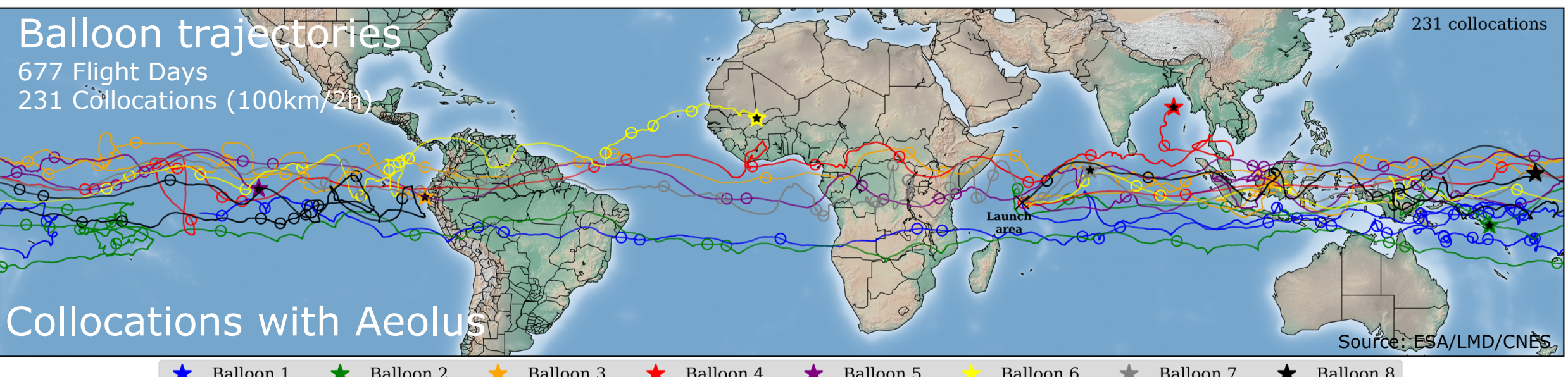




\section{Aeolus Tropical Campaign}

- Largest impact of the Aeolus observations expected in the Tropics and in particular over the Tropical oceans

- Airborne Campaign in Cape Verde/Tropics:

- Correlative observation between Aeolus and the airborne and ground-based remote sensing and in-situ reference systems

- Tropical wind systems, e.g., Easterly Waves, ITCZ

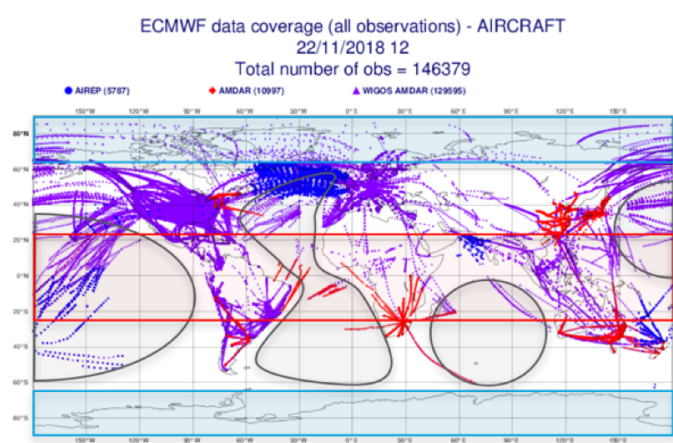

- Aerosols, i.e., Saharan dust

- Tropical clouds and convection

- Providing proxy data for EarthCARE E2E

- Planning prepared for July 2020

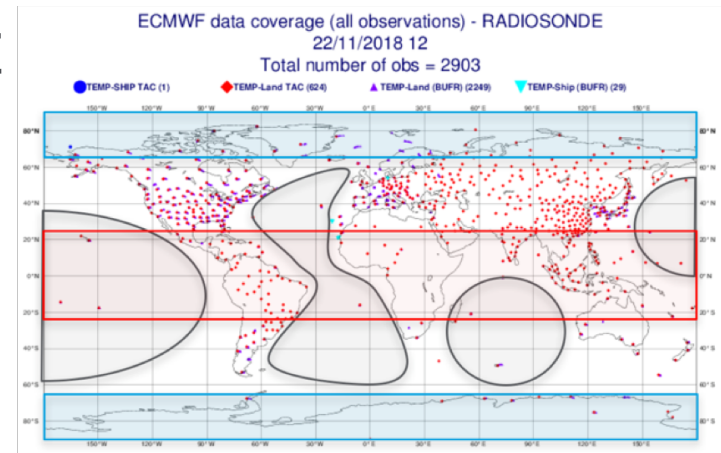




\section{Aeolus Tropical Campaign}

- Largest impact of th Aec chs vations expected in the Tropics and in parm lar by the ropi poceans

- Airborne Camp in

- Correlate airl in-situ refe

- Tropicar Campaign moved

- Aerosc.sico to July 2021

COVID-19

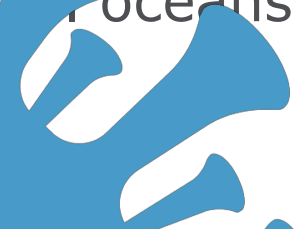
Juc id the ensing and

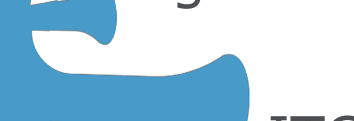

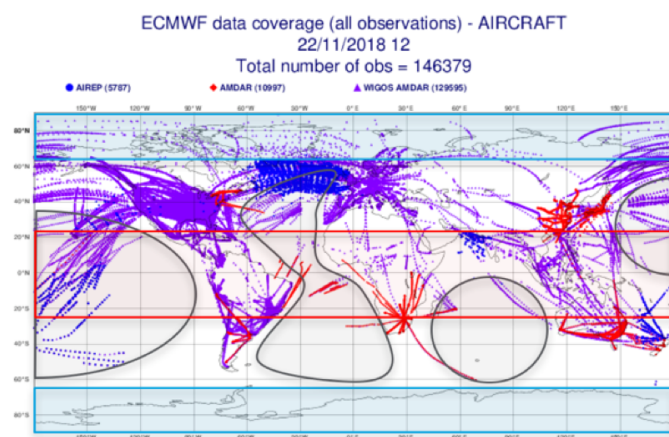

ECMWF data coverage (all observations) - RADIOSONDE

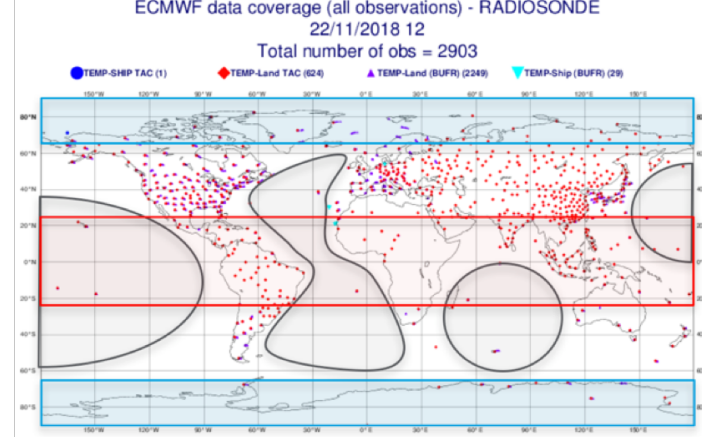

- Tropical cl

- Providi próy

- Planning prep d for 


\section{Wind Systems, dust and clouds}

Cesa
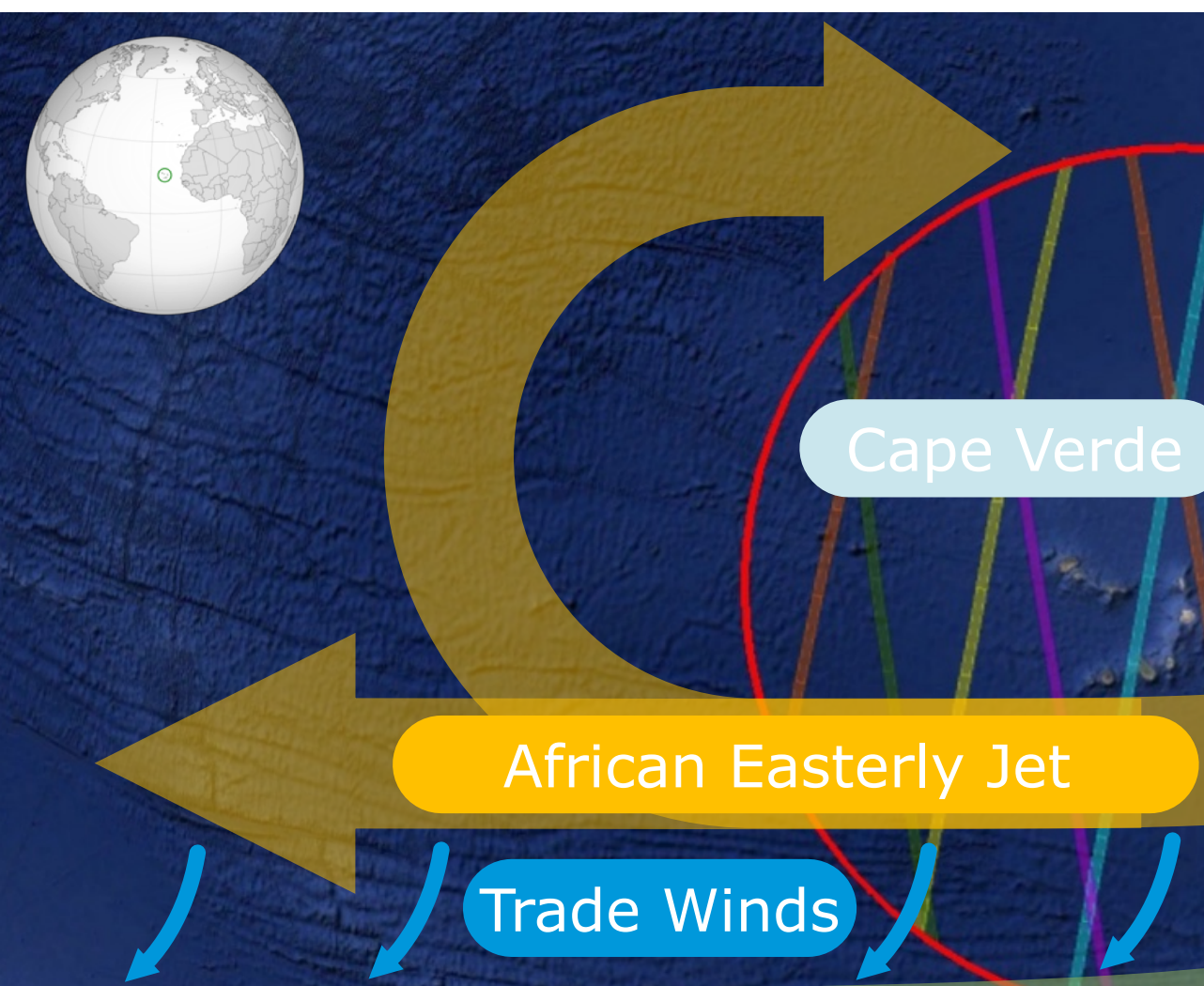

African Easterly Waves

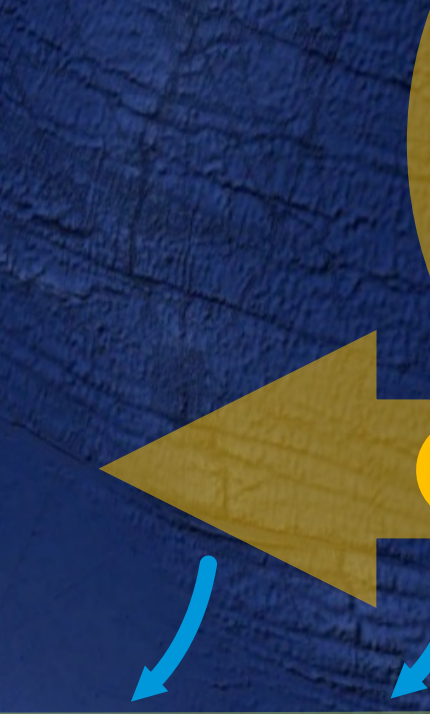

Trade Winds

ITCZ

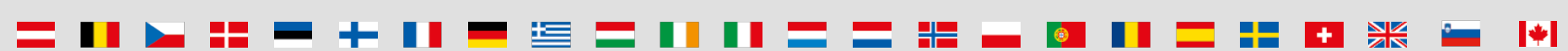




\section{Wind Systems, dust and clouds}

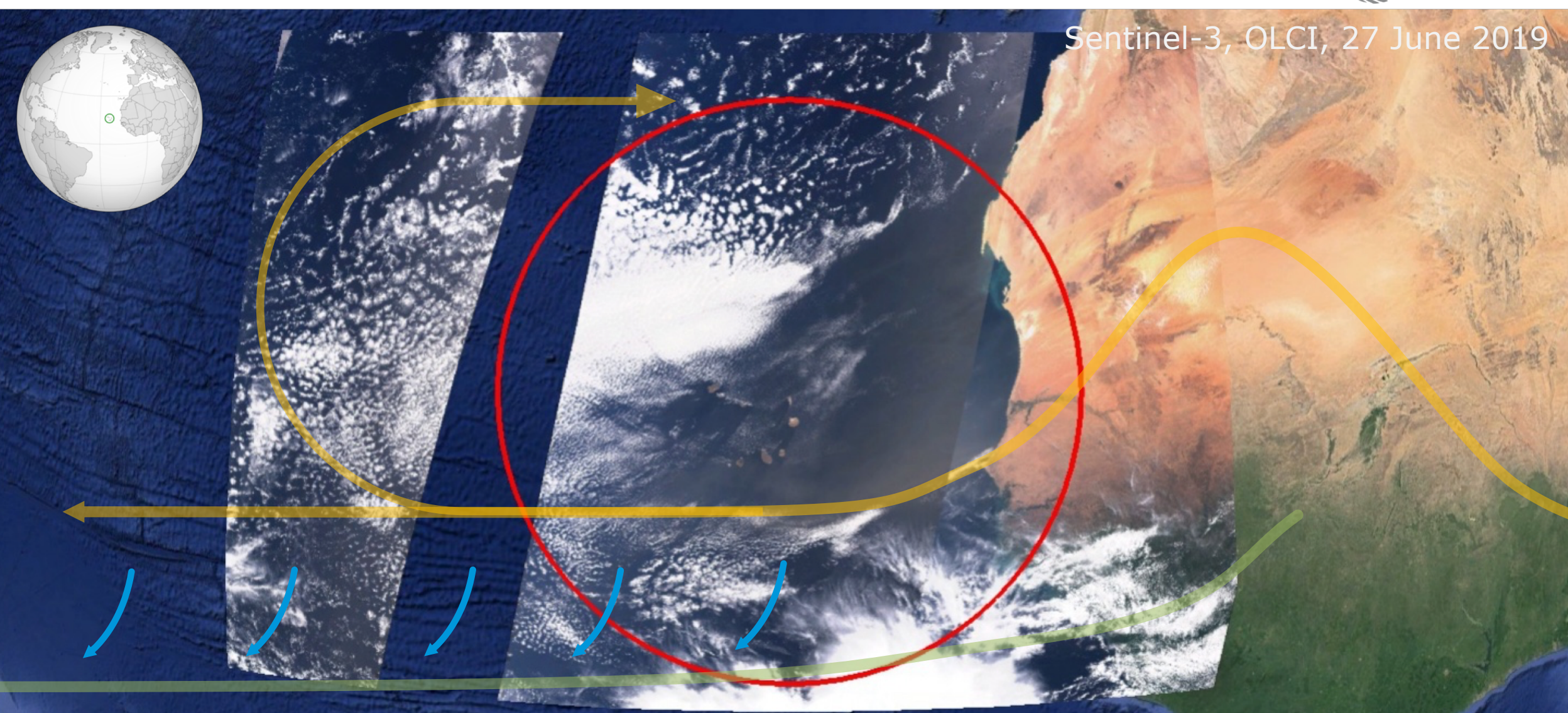

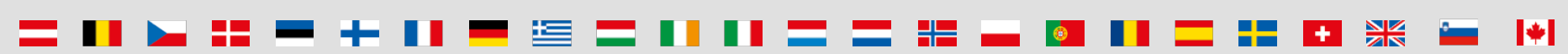


Wind Systems, dust and clouds

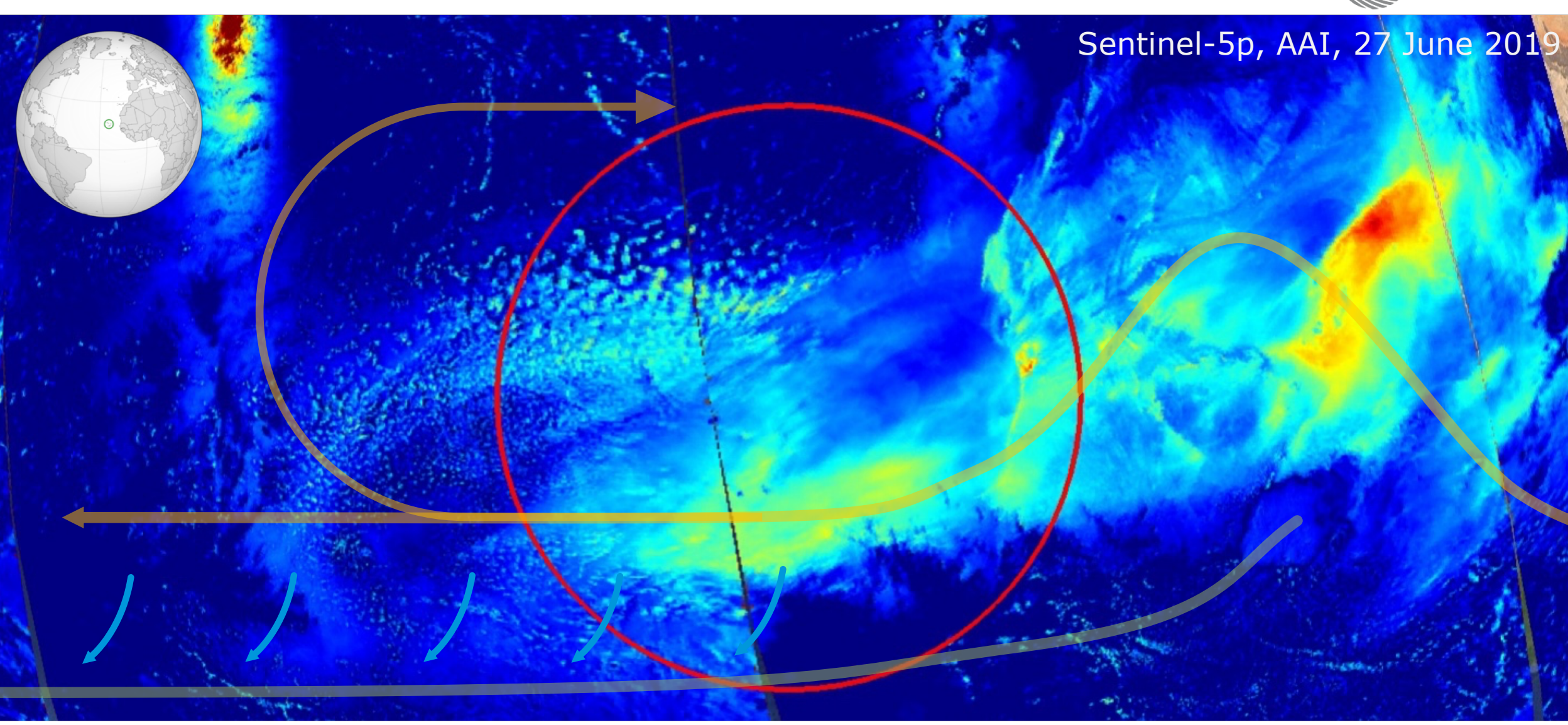

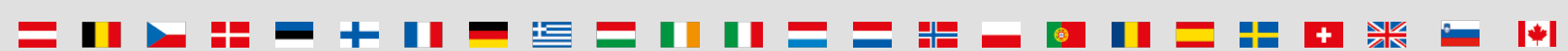




\section{Tropical Campaign 2021 - Projects and Participants 1 esa}

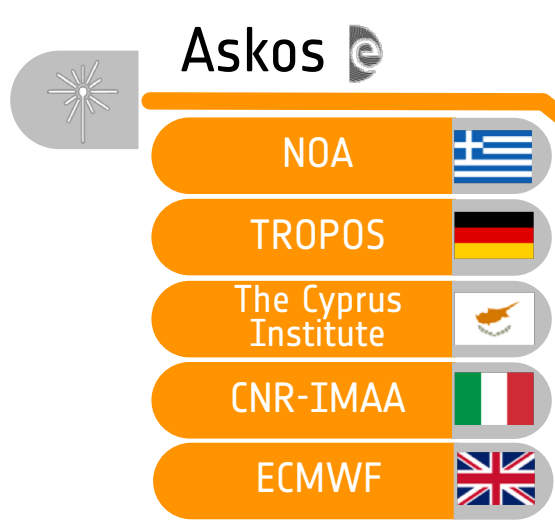

Light Aircraft ec

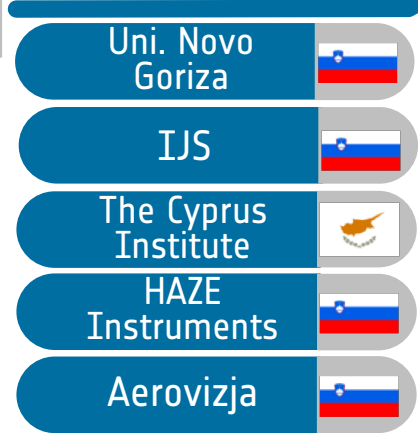

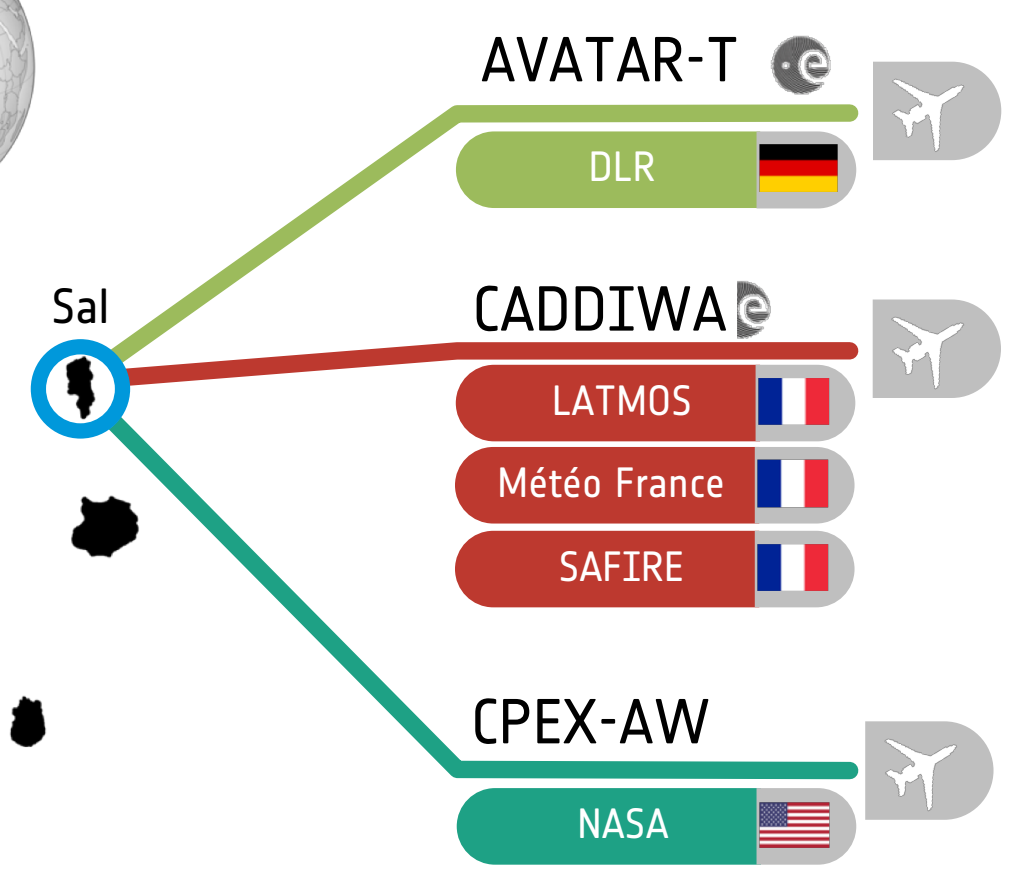


Tropical Campaign 2021- Airborne Fleet cesa

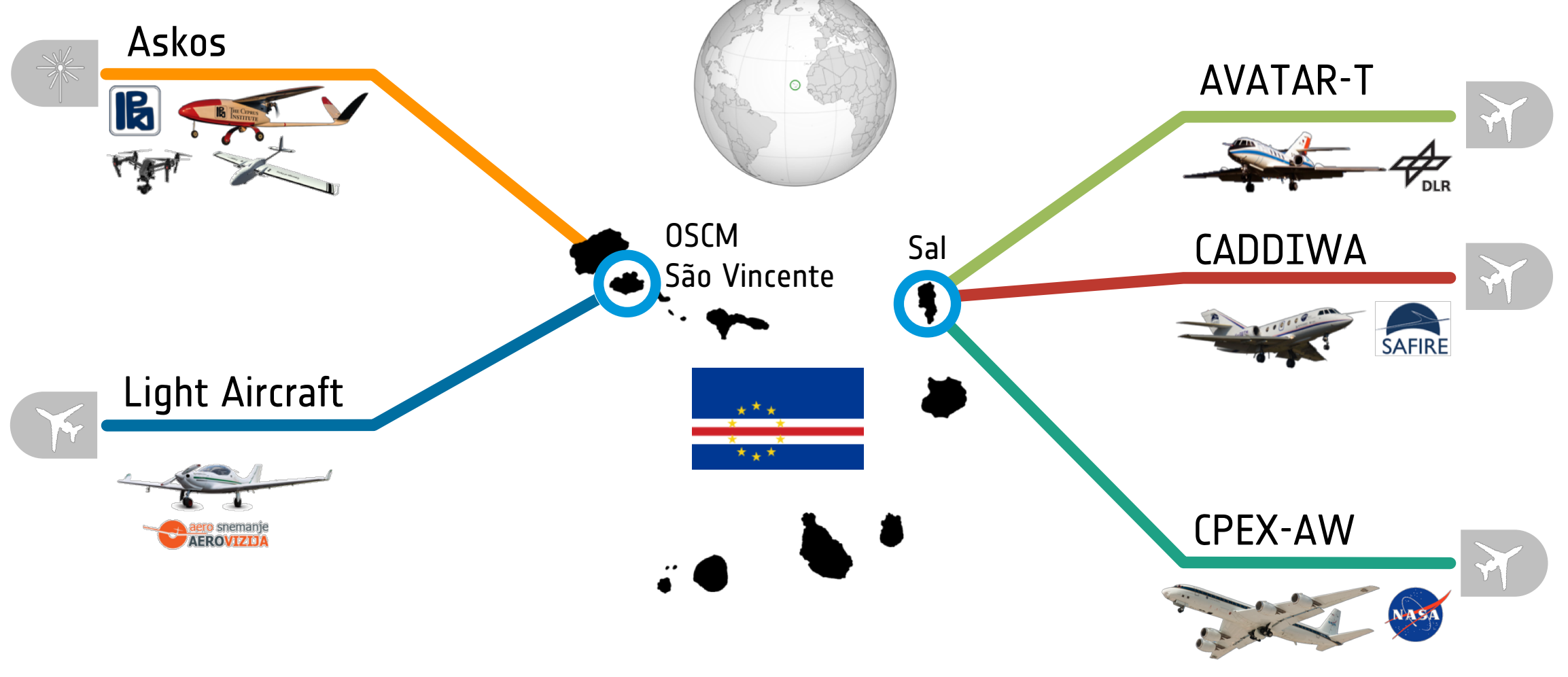


Tropical Campaign 2021 - Instruments (prelim.)

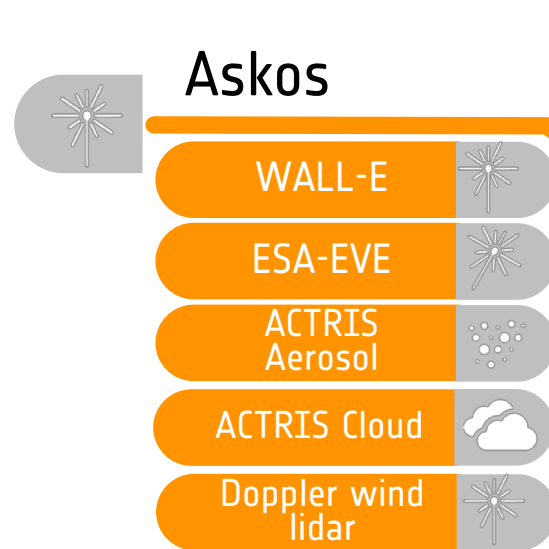
Light Aircraft

\begin{tabular}{|c|c|}
\hline Nephelometers & $\because \because 0$ \\
\hline Filter light & $\because \because 0$ \\
abs. photom. & $\because$ \\
\hline $\begin{array}{c}\text { Optical particle } \\
\text { counters }\end{array}$ & $\because$ \\
\hline
\end{tabular}

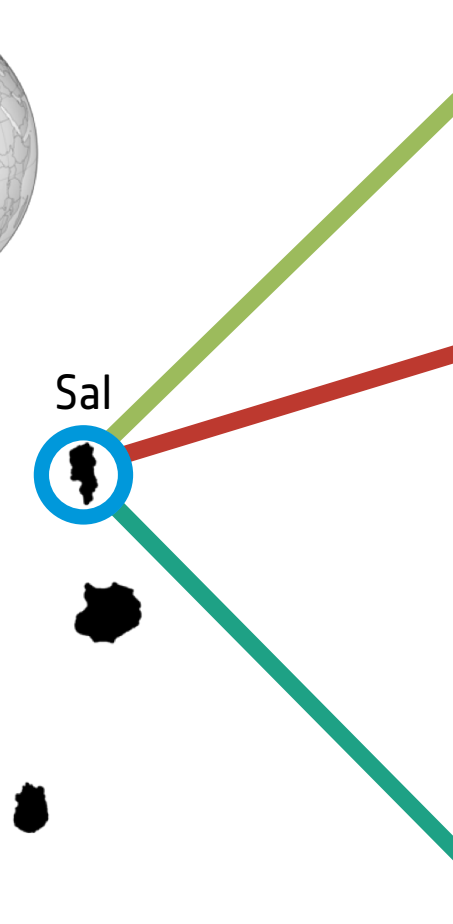

AVATAR-T

\section{A2D}

$2 \mu \mathrm{m}$-DWL

CADDIWA

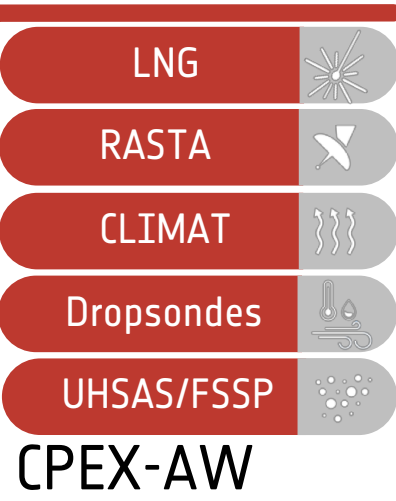

DAWN

HALO

APR-3

Dropsondes

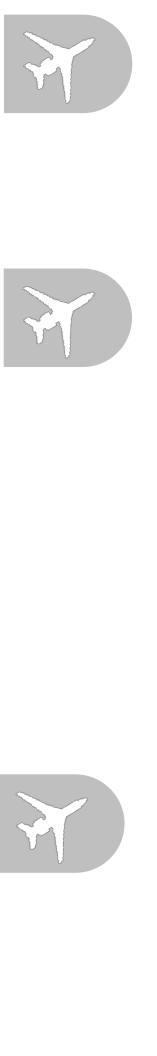

Slide 21

ESA UNCLASSIFIED - For Official Use Aeolus Validation and Science

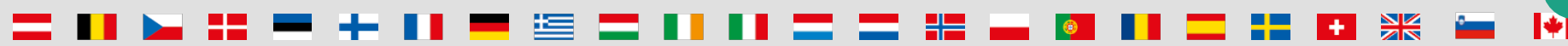




\section{Conclusion \& Outlook}

Campaigns are an important tool supporting the Aeolus mission

- Supporting the processor and instrument developments during mission development

- Providing perfectly collocated observations for the in-orbit calibration and validation

- Establishing reference data for future mission developments and science communities

- Responding to recommendations from the instrument experts and Science Advisory Group

\section{Future Perspectives}

- Successful implementation of the Tropical Campaign 2021

- Identification of campaign needs for further product improvement (e.g., L2A products)

- Evolution of airborne instruments and campaign to support Aeolus-FO activities
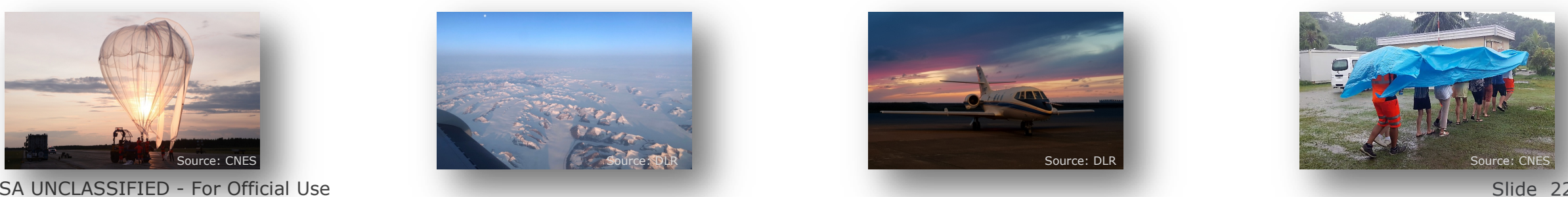